OPEN ACCESS

Edited by:

Kazuki Saito,

RIKEN Center for Sustainable Resource Science (CSRS), Japan

Reviewed by:

Alex Williams,

University of Sheffield,

United Kingdom

Masami Yokota Hirai,

RIKEN Center for Sustainable Resource Science (CSRS), Japan

*Correspondence:

Jens Schwachtje

schw8je@gmail.com

Specialty section:

This article was submitted to

Plant Metabolism and

Chemodiversity,

a section of the journal

Frontiers in Plant Science

Received: 28 September 2018

Accepted: 23 January 2019

Published: 13 February 2019

Citation:

Schwachtje J, Whitcomb SJ, Firmino AAP, Zuther E, Hincha DK and Kopka J (2019) Induced, Imprinted, and Primed Responses

to Changing Environments:

Does Metabolism Store and

Process Information?

Front. Plant Sci. 10:106.

doi: 10.3389/fpls.2019.00106

\section{Induced, Imprinted, and Primed Responses to Changing Environments: Does Metabolism Store and Process Information?}

\author{
Jens Schwachtje*, Sarah J. Whitcomb, Alexandre Augusto Pereira Firmino, Ellen Zuther, \\ Dirk K. Hincha and Joachim Kopka
}

Department of Molecular Physiology, Applied Metabolome Analysis, Max-Planck-Institute of Molecular Plant Physiology, Potsdam, Germany

Metabolism is the system layer that determines growth by the rate of matter uptake and conversion into biomass. The scaffold of enzymatic reaction rates drives the metabolic network in a given physico-chemical environment. In response to the diverse environmental stresses, plants have evolved the capability of integrating macro- and micro-environmental events to be prepared, i.e., to be primed for upcoming environmental challenges. The hierarchical view on stress signaling, where metabolites are seen as final downstream products, has recently been complemented by findings that metabolites themselves function as stress signals. We present a systematic concept of metabolic responses that are induced by environmental stresses and persist in the plant system. Such metabolic imprints may prime metabolic responses of plants for subsequent environmental stresses. We describe response types with examples of biotic and abiotic environmental stresses and suggest that plants use metabolic imprints, the metabolic changes that last beyond recovery from stress events, and priming, the imprints that function to prepare for upcoming stresses, to integrate diverse environmental stress histories. As a consequence, even genetically identical plants should be studied and understood as phenotypically plastic organisms that continuously adjust their metabolic state in response to their individually experienced local environment. To explore the occurrence and to unravel functions of metabolic imprints, we encourage researchers to extend stress studies by including detailed metabolic and stress response monitoring into extended recovery phases.

\section{Keywords: priming, stress response, stress signaling, metabolism, metabolic imprint, plant physiology}

\section{INTRODUCTION}

Sessile plants are forced to respond to adverse biotic and abiotic conditions in their local environment. Depending on the nature and intensity of such conditions, a plant's physiology can change markedly, generally because of stress-activated signaling that leads to specific physiological responses. These responses protect against or mitigate deleterious effects of stress. In a top-to-bottom view, stress-related cues induce signaling cascades, followed by activities at genetic and protein levels. Metabolite changes are generally considered to be the last step in this event cascade. Typically, large parts of metabolism 
are affected. Stress-related cues may directly influence enzyme activities that modify the metabolic state, independent of the transcription/ translation machinery. Finally, metabolic changes result from cues that do not induce classical stress-signaling. Such direct changes of metabolism are caused by the fluctuating physico-chemical environment of a plant, such as varying climate parameters, e.g., temperature, or soil properties (Hawkes and Sullivan, 2001; De Deyn et al., 2008; Sampaio et al., 2015; Onwuka and Mang, 2018).

Most environmental stresses are transient, such as temporally limited temperature extremes or drought phases, insect attacks or microbial infections. After a stress has ended, plants may recover from the stress and reset metabolism to growth and reproduction modes; however, recovery may not be complete. Even short-term environmental stress may have long-lasting effects on the plant system. A growing number of studies suggest that storing information about a past stress event benefits plants by preparing them for the same or a similar stress in the future. This phenomenon is called priming (Frost et al., 2008; Gamir et al., 2014a; Conrath et al., 2015; Hilker et al., 2015; Mauch-Mani et al., 2017). Several plant priming mechanisms are well investigated (Table 1).

Priming mechanisms are described at different levels: at the epigenetic level (e.g., by DNA and histone modification) and at the transcript or protein level (e.g., persisting changes in the abundance of transcripts, including transcription factors, and proteins or modulation of enzyme activities). However, the metabolic level as a mediator of priming has remained largely unexplored, even though large parts of metabolism are altered during stress (e.g., Schwachtje and Baldwin, 2006; Bolton, 2009; Krasensky and Jonak, 2012; Fraire-Velázquez and Balderas-Hernández, 2013). Here, we hypothesize that persistent stress-induced changes in metabolite concentrations,

TABLE 1 | Examples of stress priming scenarios. Many abiotic and biotic stresses lead to imprints that improve the plant's response to a subsequent stress.

\begin{tabular}{lll}
\hline Priming stress & Induction by & Reference \\
\hline Biotic/insect & $\begin{array}{l}\text { Feeding } \\
\text { Oviposition } \\
\text { Volatiles }\end{array}$ & $\begin{array}{l}\text { Frost et al., 2008 } \\
\text { Bandoly et al., 2016 } \\
\text { Engelberth et al., 2004 }\end{array}$ \\
\hline Biotic/microorganism & Pathogens (SAR) & Jaskiewicz et al., 2011; \\
& & Dempsey and Klessig, \\
& Rhizobacteria (ISR) & 2012; Zeier, 2013 \\
& van Loon, 2007; \\
& Symbiotic fungi & Pozo et al., 2009 \\
\hline Abiotic & Cold/freezing & Thomashow, 1999; Guy, \\
& 2003; Hincha and Zuther, \\
& 2014; Zuther et al., 2018 \\
& Salt & Sani et al., 2013 \\
Heat & Stief et al., 2014; \\
& Bäurle, 2016 \\
& Ding et al., 2012
\end{tabular}

Other stimuli

$\beta$-Aminobutyric acid

Salicylic acid

Zimmerli et al., 2001

Seed priming with

different techniques metabolite ratios, or metabolic fluxes represent a metabolic imprint of prior environmental impacts and that these imprints can prime responses to future environmental events. We present evidence that supports our hypothesis and suggest environmental shift experiments that not only monitor metabolic responses during a first stress exposure (the priming event) or during a second stress response (the primed response), but also monitor short- and long-term recovery phases after stress events. Such experimental designs may characterize and identify functions of metabolic imprints at the level of metabolic priming.

Metabolite-primed responses are only properly defined by the timing, nature, and dose of the preceding environmental change, the duration of the recovery period, and in addition by the nature and dose of the subsequent stress for which metabolism is primed. In agreement with generalized concepts of non-metabolic primed stress responses (Hilker et al., 2015), several scenarios of metabolite-primed stress responses are conceivable:

1. The primed response may be stronger than the non-primed response level. As a result, defense or tolerance mechanisms can be amplified.

2. The primed response rate may be accelerated and reach effective response levels earlier.

3. The primed response is initiated earlier. In this case, the system's response rate may remain unchanged, but the effective levels of response are reached earlier.

4. Primed responses may be triggered by a lower stress dose.

These scenarios are thought to be generally applicable and have been recently discussed (Hilker et al., 2015). In the following, we focus on the roles of metabolites during stress responses, recovery, and priming. We shortly highlight effects of metabolites at all system levels of plant physiology and subsequently review metabolic changes that are caused by stress and last during stress recovery as metabolic imprints. We link metabolic imprints to a wide range of abiotic and biotic stresses. Finally, we discuss experimental approaches that enable discovery of metabolic imprints and functional analyses of these imprints.

\section{INDUCED METABOLIC RESPONSES}

Changes in the biotic and abiotic environment are reflected by the metabolic state of a plant. Plants have a multitude of plastic responses hardwired into their genomes (Sultan, 2000). These responses are induced concomitantly with the stress and function as defense, tolerance, or repair mechanisms (e.g., Dangl and Jones, 2001; Suzuki et al., 2011; Schuman and Baldwin, 2015). These mechanisms can be defined as stresssignaling dependent metabolic responses. Additionally, physical and chemical conditions such as temperature and soil nutrients influence metabolism, albeit mostly to a lesser degree than stresses. Temperature affects all reaction and transport rates. Soil nutrients influence physiology according to their availability. Consequently, changes in the physico-chemical environment of a plant will cause concomitant metabolic responses which 


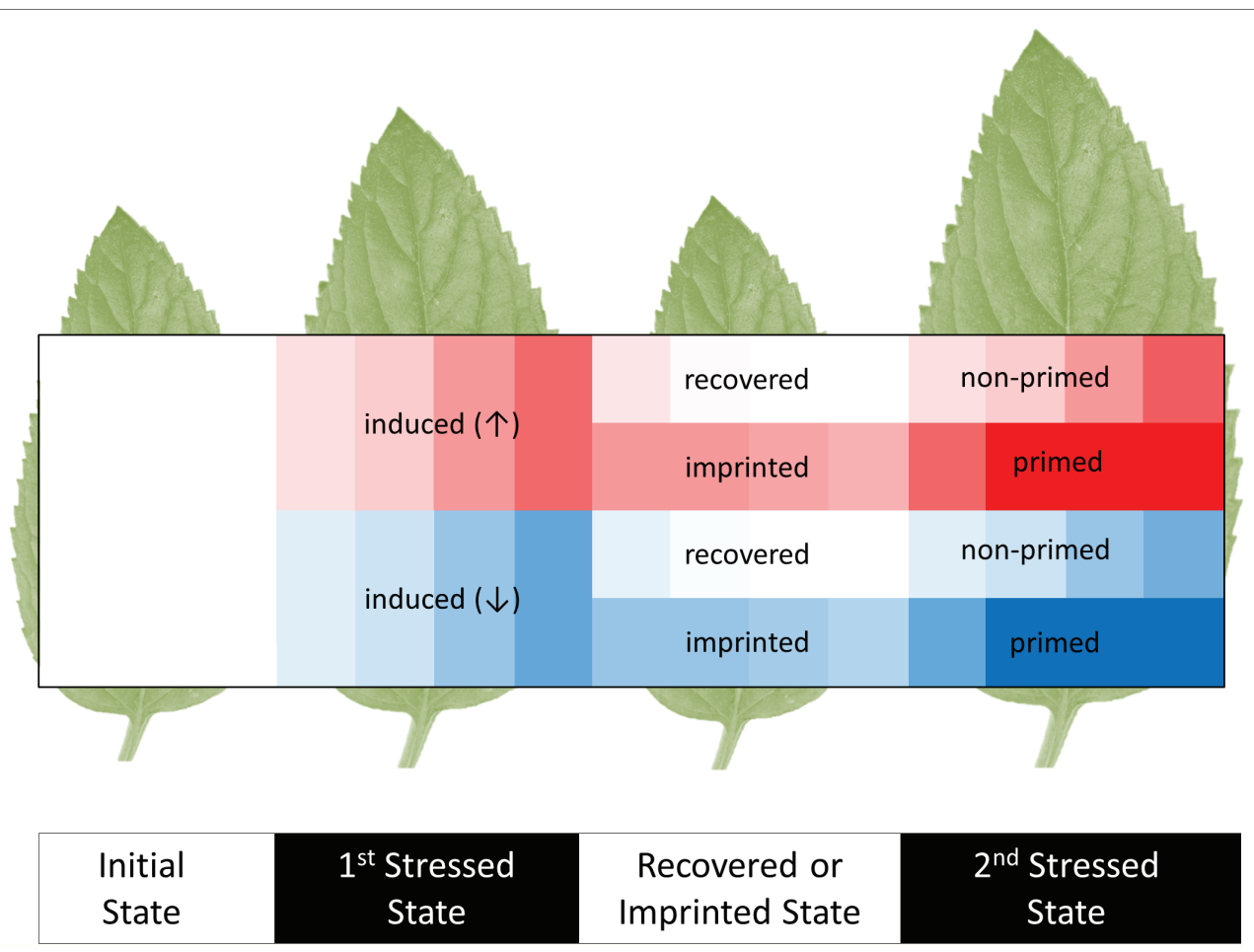

FIGURE 1 | Scheme of initial, induced, imprinted, and primed metabolic responses to recurrent abiotic or biotic stresses. The heat map shows increases ( $\uparrow$, red) and decreases ( $\downarrow$, blue) of metabolite levels relative to the pre-stressed, initial metabolic state (white). Most induced responses that are caused by a first stress period subsequently recover to the initial metabolic states. Few metabolic changes are retained. We argue that these metabolic imprints may be used as a memory that stores and processes information of preceding stress histories. These processes may contribute to stress priming. A primed response to a second stress enables organisms to cope better with recurrent stresses. Parts of the primed metabolic responses can be more sensitive, earlier, faster, or result in more extreme changes of metabolite levels. Note that imprinted metabolites may not necessarily have primed responses. Indeed, metabolic imprints during recovery without prior induction and primed responses without prior metabolic induction or imprinting are conceivable.

influence single or multiple nutrient fluxes through the plant system. These changes may ultimately become apparent as changes in metabolic pool sizes or fluxes. Therefore, induced metabolic responses need to be interpreted as the synergistic effects of stress-signaling dependent plant responses and of external physico-chemical influences.

The study of induced metabolic responses implies an initial metabolic state that transitions into an induced metabolic state (Figure 1); however, these states cannot be viewed as steady states, because they are integrated into non-static physiological processes governed by diurnal environmental cycles, circadian rhythms, and developmental progression of specific tissues and of the whole plant system. Due to these interactions, any observed induced metabolic response may represent a direct modification of metabolism that is on top of the underlying physiological programs of the plant.

\section{METABOLIC IMPRINTS AND METABOLIC MEMORY}

After an environmental stress has ceased, plant metabolism typically returns to a recovered state that is highly similar to the initial state (e.g., Hemme et al., 2014; Crisp et al., 2016; Pagter et al., 2017). A very basic metabolic perturbation and recovery process may resemble a hysteresis curve, where the metabolic transition during the perturbation and recovery take characteristically different paths. The kinetics of metabolic remodeling are largely dependent on the nature of the environmental stress, transcriptional activities, the architecture of the affected metabolic networks, and the set of transport rates and enzyme activities that act on the induced metabolite levels. As an example of differential metabolic remodeling kinetics, glycolysis intermediates reached pre-stress levels quicker than TCA cycle intermediates in Arabidopsis roots upon recovery from oxidative stress (Lehmann et al., 2012).

Some induced metabolic responses may persist after the global metabolic state of the plant has recovered to the initial state (Figure 1). A simple case would be delayed adjustment of a metabolite to the initial state. Such a delay causes a metabolite to be more abundant at the onset of a second stress event. Furthermore, some induced metabolic responses may be effectively permanent or even cumulative, e.g., due to the absence of a catabolic pathway or sequestration mechanism (Mackie et al., 2013). Two phases of metabolic response are evident: (1) metabolic changes that are induced as immediate, specific responses to the stress, e.g., sugar levels, sucrose/hexose ratio, precursors for secondary metabolites or energy-related metabolites. During stress recovery (2) some of these changes may last as mid- or long-term imprints. Imprints may influence upcoming stress 
responses. Here, we define metabolic imprints to encompass all metabolic changes that persist after recovery and thus differentiate the imprinted from the initial, pre-stress state.

According to this definition, metabolic imprints are indicators of past environmental conditions and/or stress events. In this sense, metabolic imprints may store information. Imprinted information becomes metabolic memory, when it is maintained and used by the plant system to improve future stress responses, for example to enhance or accelerate metabolite-induced signaling (Thellier and Lüttge, 2013). Metabolic imprints may be caused by one or more environmental events in the individual history of a plant. Metabolic imprints have been postulated previously to act as a stress memory (Bruce et al., 2007). A metabolic memory may act alone or more likely in synergy with priming and memory mechanisms at other system levels that are highlighted in the following.

\section{METABOLITES INFLUENCE BIOLOGICAL SYSTEMS AT ALL LEVELS}

If metabolites are involved in stress responses and represent stored information, metabolites should in turn influence metabolic or signaling pathways and other parts of plant physiology to modify a stress response. Generally, stress metabolism is seen as hierarchically organized, where external cues initiate signaling pathways that via transcription, translation, posttranslational modifications such as phosphorylation and further regulatory steps ultimately affect metabolism. Metabolites are generally thought to represent the downstream "end" products of this hierarchy. Interestingly, this view is currently complemented by findings that suggest bottom-to-top signaling mechanisms. Specific metabolites can exert regulatory influence or feedback on the stress-signaling network and physiology. Such mechanisms open possibilities for cross talk between stress-induced metabolites and other levels of physiological regulation (Bonawitz et al., 2012; Farre and Weise, 2012; Xiao et al., 2012; Gaudinier et al., 2015; Katz et al., 2015; Francisco et al., 2016; Malinovski et al., 2017). Further complexity is indicated by fluxes of central metabolism that are not necessarily explained by transcript abundances of the corresponding enzymes (Chubukov et al., 2013; Schwender et al., 2014). In addition to classical allosteric feedback responses, such as the suppression of enzyme activity by high levels of reaction products, metabolite ratios, and possibly also metabolite fluxes may thus play important roles by directly affecting multiple levels of the stress response hierarchy.

For example, branched chain amino acids are required for phosphorylation of $\mathrm{G}$ proteins during osmotic stress signaling in yeast (Shellhammer et al., 2017). Other findings suggest that certain primary metabolites can influence physiology at the transcriptional level. In yeast, Pinson et al. (2009) found that a metabolic intermediate of purine metabolism influences the interaction of transcription factors and thereby modulates purine and phosphate metabolism. Amino acids and polyamines are suggested to directly modify translation because they can be sensed by translating ribosomes via interactions with nascent polypeptides, specifically with so-called arrest peptides (Seip and Innis, 2016). Furthermore, several metabolites are cofactors or co-substrates of chromatin-modifying enzymes and thus represent a potential regulatory interface between the metabolic and chromatin states of the cell (Shen et al., 2016; Van der Knaap and Verrijzer, 2016). For some primary metabolites, a role in chromatin modulation is suggested, e.g., fumarate, succinate, $\alpha$-ketoglutarate, and acetyl-CoA. Fumarate, for example, is a competitive inhibitor of $\alpha$-ketoglutarate, which is a co-substrate of histone demethylases and TET DNA methylases. Changes in cellular fumarate levels or ratios of fumarate, e.g., to ketoglutarate, may therefore contribute to altered histone modification. Different methylated histone residues are sensitive to changes in the $\alpha$-ketoglutarate/ succinate ratio (Van der Knaap and Verrijzer, 2016). These effects may be specific for certain genetic regions.

The TOR and SnRK kinases are sensors of the cellular energy state and can regulate large parts of metabolism. Plants adapt to changes in energy requirements during stress using these sensors (Baena-González, 2010; Hey et al., 2010; Rexin et al., 2015). The kinases are suggested to respond to sugars and other metabolites, even though the molecular mechanisms are not yet unraveled in all details. TOR is known to be regulated by nutrient sensing of nitrogen and carbon metabolites in plants, yeast, and mammals (e.g., Dobrenel et al., 2016; González and Hall, 2017). But plant defense metabolites of the glucosinolate family, 3-hydroxypropylglucosinolate, and/or its derivatives, can also activate TOR kinases (Malinovski et al., 2017). A precursor of plastidial isoprenoids that is induced by abiotic stress can induce nuclear stress-responsive genes via retrograde signaling (Xiao et al., 2012). The mediator complex, which regulates gene transcription, is involved in phenylpropanoid metabolism and is suggested to respond in a feedback loop to changes in this defense-related class of compounds (Gaudinier et al., 2015).

\section{METABOLITES AND STRESS RESPONSES}

Metabolic responses to stress are ubiquitous and well described for many plant systems. Time-series experiments revealed that metabolic activities can respond to stress more quickly than transcriptional activities (Kaplan et al., 2007; Guy et al., 2008; Caldana et al., 2011; Fraire-Velázquez and Balderas-Hernández, 2013), thus making metabolic changes an important part of early stress responses. Several metabolites can directly influence plant stress responses (Rojas et al., 2014). A few important examples are discussed below.

\section{Carbohydrate Metabolism}

During freezing and drought, soluble sugars, such as sucrose, trehalose, fructans (fructose-based oligo- and polysaccharides), and the raffinose family of oligosaccharides can stabilize phospholipid membrane vesicles (Hincha et al., 2006; Livingston et al., 2009; Tarkowski and Van den Ende, 2015). Several sugars 
emerged as important factors also during biotic stress signaling (Baena-González and Sheen, 2008; Figueroa and Lunn, 2016; Li and Sheen, 2016). Sucrose has been shown to regulate various stress-related responses including circadian clock genes, phytohormones, energy metabolism, cell wall and anthocyanin synthesis (Thibaud et al., 2004; Gomez-Ariza et al., 2007; Tognetti et al., 2013; Tauzin and Giardina, 2014). Glucose induces the pathogen defense proteins PR-1 and PR-5 in Arabidopsis via hexokinase1 (HXK1) signaling (Xiao et al., 2000; Moore et al., 2003; Cho et al., 2009). For fructose, a specific pathway has been proposed that involves abscisic acid and ethylene signaling (Cho and Yoo, 2011; Li et al., 2011). Engelsdorf et al. (2013) showed that carbohydrate availability influences defense against a hemibiotrophic fungus during its necrotrophic phase. The more carbohydrate is available, the better the plant defends. Similarly, increased relative fructose content enhances defense against the pathogen Botrytis cinerea in tomato (Lecompte et al., 2017). Besides the importance of sugars for stress signaling, plants organize sugar distribution in a way that pathogens have reduced access to carbohydrates. Local depletion of nutrients appears to cause a starvation effect that reduces pathogen propagation (Bezruczyk et al., 2018).

\section{Amino Acid Pathways}

In a 2010 paper, Liu and colleagues knocked out the amino acid transporter lht1 and correlated cellular depletion of the amino acid glutamine with altered redox status and more effective defense against several pathogens (Liu et al., 2010). These authors proposed a yet unknown negative effect of glutamine on defense signaling and a reduction in the pathogen's access to essential nutrients, similar to recent findings on Pseudomonas-primed systemic responses of Arabidopsis (Schwachtje et al., 2018). Stuttmann et al. (2011) described threonine as a potential growth inhibitor of the biotrophic oomycete Hyaloperonospora arabidopsidis, even though the underlying mechanism is yet unknown. It is suggested that indole-3-carboxylic acid activates defenses against Plectosphaerella cucumerina in Arabidopsis by inducing papillae deposition and $\mathrm{H}_{2} \mathrm{O}_{2}$ production, independently of salicylic acid and jasmonic acid (Gamir et al., 2014b). $\boldsymbol{\gamma}$-Aminobutyric acid (GABA) interacts with quorum sensing of Agrobacterium tumefaciens, thus reducing pathogen virulence in tobacco (Chevrot et al., 2006). GABA also functions as a direct anti-herbivore defense in Arabidopsis (Scholz et al., 2015). Furthermore, the proline and the pyrroline5-carboxylate (P5C) cycle are crucial for defense responses against pathogens and abiotic stresses (Liang et al., 2013; Qamar et al., 2015). Proline is involved in redox balance, osmoprotection, and stress signaling (Szabados and Savouré, 2009).

\section{Polyamine Metabolism}

Polyamines (e.g., spermine, spermidine, and putrescine) are aliphatic compounds that are synthesized from amino acids (e.g., arginine and ornithine). Polyamines are involved in many crucial processes of cell metabolism and the translation/transcription machinery, and induce ROS, Ca, and NO signaling (Alcázar et al., 2010). Salt, heat, and drought stress induce genes for polyamine synthesis (Tiburcio et al., 2014; Liu et al., 2015; Miller-Fleming et al., 2015) and enhanced tolerance of abiotic stresses is correlated with elevated levels of polyamines (Alcázar et al., 2010). Putrescine induces abscisic acid synthesis at the transcriptional level during cold stress (Cuevas et al., 2008). Spermine appears to protect Arabidopsis from heat stress by increasing the expression of genes encoding heat shock proteins (Sagor et al., 2013). The pretreatment of tomato fruits with spermine before heat shock promoted an increase in expression of signal transduction genes (e.g., calmodulin, serine/threonine protein kinase) along with genes related to phytohormone pathways. Moreover, polyamines can modulate chromatin structure (Pasini et al., 2014). It is also suggested that the connected putrescine, GABA, and proline pathways play an important role during abiotic stresses (Shelp et al., 2012, Legocka et al., 2017).

\section{External Application of Natural Compounds}

A few metabolites have been shown to prime pathogen-induced stress responses when externally applied to plants, e.g., thiamine (Ahn et al., 2007), riboflavin (Zhang et al., 2009), quercetin (Jia et al., 2010), and hexanoic acid (Aranega-Bou et al., 2014). Supposedly, all have in common an activation of the redox system that supports stress signaling. In a recent study, fumarate and citrate applications were shown to induce priming against Pseudomonas syringae in Arabidopsis, in the case of fumarate without changes in classical defense-related genes and hormones (Balmer et al., 2018). Thereby, Balmer et al. (2018) confirmed an earlier observation of systemic fumarate priming upon first exposure to the bacterial pathogen (Schwachtje et al., 2018). Further, a broad induction of plant defense systems in Arabidopsis was demonstrated after the application of melatonin (Weeda et al., 2014).

\section{ARE STRESS-RELATED METABOLITES STORED IN THE VACUOLE?}

To exert a long-term effect that primes future stress responses, relevant metabolites must be stored in a way that prevents them from negatively interfering with metabolism during the recovery phase and that inhibits degradation. Accumulation of metabolites in chloroplasts, mitochondria, or in the cytosol would likely disturb core metabolic processes that are necessary for recovery (Plaxton, 2005). Possible circumventions would be a reversible conjugation that alters the chemical property of the metabolite, or storage in a membrane-enclosed cellular compartment, such as the vacuole. The vacuole can occupy more than $80 \%$ of the cell's volume and is involved in multiple critical cellular functions including storage of metabolites and modification of cytosolic metabolism according to physiological requirements (Martinoia et al., 2012). The tonoplast enclosing the vacuole contains many identified membrane proteins that are responsible for loading and unloading a diverse set of metabolites (Martinoia et al., 2012). These transporters are integrated in a larger cellular network that responds to physiological requirements and stress responses (Martinoia 
et al., 2007; Pommerrenig et al., 2018). The carboxylic acids fumarate, malate, and citrate represent major components of the vacuolar metabolome. For example, malate is transported by two proteins, a specific anion channel (Hafke et al., 2003) and a solute carrier (Emmerlich et al., 2003). Many other primary metabolites, such as amino acids and sugars, are stored in the vacuole (Neuhaus, 2007; Tohge et al., 2011; Szekowka et al., 2013; Hedrich et al., 2015). Vacuoles are also involved in plant defenses against herbivores and pathogens by storing and sequestering toxic metabolites. Thus, specific analyses of vacuolar metabolite compositions, e.g., by non-aqueous fractionation (Klie et al., 2011), are required to unravel a possible long-term storage of stress-induced metabolites that represent metabolic imprints and may function as a metabolic memory.

\section{EXAMPLES OF STRESS-INDUCED METABOLIC IMPRINTS}

The functional analysis of stress-induced metabolic responses has been a long-standing focus of plant physiology. In contrast, metabolic imprints following stress have rarely received attention but can now be described and analyzed in detail by large-scale experiments that combine metabolic phenotyping with global screening of other system levels and physiological analyses (e.g., Hemme et al., 2014). The fragmented knowledge on recovery processes may result from the simplifying assumption that plants will revert to the identical initial endogenous state after a transient environmental perturbation. The resetting of the initial state is thought to alleviate the need to expend energy for the maintenance of the stress-adapted state. While this assumption may be correct for the majority of metabolites, the past perturbations may leave an imprint on metabolism that lasts longer than may be expected from a system level that is notorious for its extremely rapid fluctuations (Urbanczyk-Wochniak et al., 2005; Kim et al., 2011). In the following, we will review evidence of metabolic imprinting and functions of imprints for priming of systems in the context of abiotic and biotic stresses.

\section{Abiotic Stress}

Abiotic stresses are known to prime plant systems for an enhanced stress response to a recurrent stress. Recent reviews highlight abiotic stress priming of temperature, drought, and other factors (Bruce et al., 2007; Hincha and Zuther, 2014; Hilker et al., 2015). In the following, we will first highlight proline imprints that were observed in the context of various stresses before we address more stress-specific metabolic imprints.

\section{Proline Imprints Are Caused by Various Abiotic Stresses}

Proline accumulation is one of the most studied metabolic stress responses. Upon environmental stress, proline is mainly generated from glutamic acid in chloroplasts and increases up to 100 -fold in plants (Liang et al., 2013). Proline has several functions during stress responses, e.g., as an osmoprotectant, antioxidant, molecular chaperone to protect protein integrity, $\mathrm{pH}$ buffer, or in some cases it may serve as a carbon and nitrogen source during stress recovery. Proline also enhances enzyme activities, triggers gene expression, and modulates mitochondrial functions (Szabados and Savouré, 2009). By increasing ROS production in mitochondria via the electron transport chain, proline regulates processes that support cell survival or induce apoptosis (Liang et al., 2013). Suppression of proline catabolism, for example via reduction of proline dehydrogenase gene expression, enhances tolerance toward salt and drought stress (Ibragimova et al., 2012). In Arabidopsis, proline accumulates strongly during a 4-day drought phase and declines to initial levels during a subsequent 4-day recovery phase (Sharma and Verslues, 2010). In contrast, the drought-resistant Periploca sepium increases proline levels continuously during a similar 4-day drought stress but maintains a proline imprint during a 4-day recovery phase (An et al., 2013). Even after a 8 -day recovery, the newly developed buds of Periploca sepium still contained twice as much proline as control plants. Proline is apparently also important for recovery of tobacco plants from drought stress by suppressing a senescence-related promoter (Vancova et al., 2012). In addition, the proline concentration in salt stress-resistant salt cress (Thellungiella halophila, renamed to Thellungiella salsuginea, and Eutrema salsugineum) is significantly higher than in Arabidopsis already under control conditions (Taji et al., 2004; Benina et al., 2013; Lee et al., 2016). In this case, high proline levels may serve as a constitutive stress adaptation of an extremophile plant. Also, in T. halophila, proline levels increased during a 3-day recovery from cold stress but not during the 3-day stress phase itself. The imprint of the proline pool is accompanied by other metabolites, such as 5-hydroxyproline and sucrose (Benina et al., 2013). In Arabidopsis, 3 days after de-acclimation from cold acclimation, proline levels were still elevated in leaves. More freeze-tolerant Arabidopsis accessions showed higher levels than susceptible accessions after 3 days of recovery (Zuther et al., 2015).

\section{Drought}

Several studies describe imprints of metabolite pools other than proline after exposure to drought. Primary metabolites, e.g., sugars and organic acids, as well as several secondary metabolites maintain a characteristic imprint in the resurrection plant Haberlea rhodopensis after 2 days of recovery from an 8-day drought period (Moyankova et al., 2014). A similar duration of drought stress and recovery, 8-10-day stress and 2-day recovery, causes a different metabolic imprint of Medicago sativa nodules (Naya et al., 2007). In this symbiotic system, pools of several primary metabolites remain reduced during drought recovery. A recent study describes the metabolic recovery of drought-stressed sugar beets (Wedeking et al., 2018). The authors found a transient normalization of most of the measured metabolites after 8 days of recovery from a 13-day drought stress period. Interestingly, during the following 4 days, several amino acids (e.g., phenylalanine, tyrosine, and leucine) again accumulated in leaves, indicating a metabolic stress imprint that may be beneficial for a subsequent second drought phase. 


\section{Low Temperature}

Faster than drought stress, temperature stress may rapidly revert. Temperature changes cause metabolic responses that are particularly well characterized after heat shock or extended cold exposure (e.g., Kaplan et al., 2004, 2007; Guy et al., 2008). The temperature-induced metabolic responses comprise strong changes in a wide range of metabolite pools that indicate global reprogramming of primary metabolism in Arabidopsis rosettes. Data on metabolomic and transcriptomic cold recovery describe a 24-h metabolic imprint after 4 days of exposure to $4^{\circ} \mathrm{C}$ (Kaplan et al., 2004, 2007) and reveal several interesting aspects. Firstly, most of the cold-induced transcript changes returned to the pre-stress state after $24 \mathrm{~h}$. In contrast, primary metabolism was only partially recovered. These differences between transcriptional and metabolic recovery from cold stress were recently confirmed in greater detail by Pagter et al. (2017). Secondly, the metabolite profile of the recovery phase differed significantly from all measured time points during cold exposure, supporting the observation that the metabolic reorganization after stress exhibits different kinetics than the stress response. Cold de-acclimating metabolism was associated with partially maintained enhanced freeze tolerance, which apparently remains active at least 3 days into cold-recovery (Kaplan et al., 2004; Zuther et al., 2015). Zuther et al. (2018) reported genetic differences in the transcriptomic and metabolic patterns during cold memory of the Arabidopsis ecotypes, Col-0 and N14.

A complex picture of metabolic reorganization during recovery was described after freezing stress of crown tissue of oat (Avena sativa L.) by Henson et al. (2014). After 3 weeks of cold acclimation and 1 day of freezing, plants were monitored during 14 days of recovery. At the end of recovery, several amino acids were largely increased compared to non-stressed plants, and several sugars and organic acids were reduced. Moreover, the metabolic profile differed markedly from what is observed after cold stress recovery, indicating that this overwintering species relies on specific regulations for freezing resistance.

Analyses of Hordeum vulgare also show stress-imprinted metabolites that are linked to frost tolerance (Mazucotelli et al., 2006). For example, 8-day-old barley seedlings were freeze-stressed at $-3^{\circ} \mathrm{C}$ for $16 \mathrm{~h}$ and allowed to recover for $48 \mathrm{~h}$ at $22^{\circ} \mathrm{C}$. This treatment resulted in 16-fold higher GABA levels at the end of the recovery phase. GABA and its precursor glutamate are part of the GABA-shunt that is linked to the tricarboxylic acid cycle where it bypasses two reaction steps from $\alpha$-ketoglutarate to succinate. Besides glutamate, putrescine and proline can also be catabolized via GABA (Shelp et al., 2012; Signorelli et al., 2015). The GABA-shunt has a central role in carbon/nitrogen metabolism and stress signaling, for example for cell death promotion in response to pathogens or for cold tolerance (Mazucotelli et al., 2006; Fait et al., 2007; Michaeli and Fromm, 2015). However, the role of GABA during cold-/frost-stress and possible GABA pool imprints are still not fully understood.

\section{High Temperature}

Elevated temperatures leave metabolic imprints in photosynthetic microorganisms. A recent large-scale study describes the temporal succession of heat stress responses of Chlamydomonas reinhardtii during a 24-h induction phase after shift from 25 to $42^{\circ} \mathrm{C}$ and the fate of system imprints during 8 -h recovery at $25^{\circ} \mathrm{C}$ (Hemme et al., 2014). In this experiment, cell division stopped during heat treatment and remained so during the $8 \mathrm{~h}$ of recovery, resulting in measurements that represent the metabolic state of cells that all individually experienced the heat stress. Similar to the example of $4^{\circ} \mathrm{C}$ cold stress in Arabidopsis (Kaplan et al., 2004, Pagter et al., 2017), the metabolome, as well as the proteome, recovered only in part and retained imprints, regarding, e.g., TCA intermediates and sugar phosphates. Importantly, the pattern of metabolic induction again differed from the pattern of metabolic recovery.

Besides temperature perturbations, other abiotic stresses have been shown to generate lasting imprints. A 6-h oxidative stress that was induced by menadione generated an imprint on primary metabolism in Arabidopsis roots that lasted at least $30 \mathrm{~h}$ into recovery (Lehmann et al., 2012). GABA was part of this imprint, like proline and other amino acids which remained at a high level, as well as several sugars and sugar phosphates.

\section{Biotic Stress}

Biotic stresses are perhaps the best understood stresses regarding primed plant systems. Recent reviews highlight the importance of biotic stress priming for enhanced responses toward a broad range of insects and pathogens that negatively influence plant performance and crop production (Frost et al., 2008; Conrath et al., 2015; Hilker et al., 2015; MauchMani et al., 2017). At the metabolite level, biotic priming is mainly studied with respect to volatile organic compounds, oviposition, and beneficial or pathogenic microorganisms that are associated with a plant and may prime systemic tissue. Even though it has often been shown that during biotic stresses, metabolism in local and systemic plant parts is severely affected (Schwachtje and Baldwin, 2006; Lemoine et al., 2013; Zhou et al., 2015), studies on persistent metabolic changes during and after recovery from pathogen or insect stress are rare. This applies specifically for interactions of plants with microorganisms, since these are continuously associated with the plant, either as beneficial root colonizers or as leaf pathogens, thus making a clearly defined recovery phase after a time-limited stress or induction phase unfeasible. Nevertheless, several metabolites have so far been associated with priming against biotic stresses.

Plant amino acid metabolism is well known to contribute to the priming of defense responses (Gamir et al., 2014a). For example, the lysine catabolite pipecolic acid can act as a key regulator of SAR (Návarová et al., 2012; Zeier, 2013). Several amino acids and intermediates of the TCA cycle are regulated during priming with pathogenic Pseudomonas syringae or the chemical $\beta$-aminobutyric acid, i.e., BABA (Pastor et al., 2014). The content of most amino acids was reduced in these experiments, but cysteine, methionine, tryptophan, and tyrosine were specifically induced by bacteria or BABA during $48 \mathrm{~h}$. Fumarate and malate were induced by BABA. These two organic acids were also induced 
in another study that investigated systemic priming-related effects of infection of Arabidopsis with Pseudomonas syringae (Schwachtje et al., 2018). A systemic increase of fumarate and malate was observed for 4 days, whereas the transcriptional profile did not explain the altered metabolite levels. This study suggested a lasting metabolic priming effect in systemic tissue that includes storage of metabolites, e.g., fumarate and malate. These metabolites may be readily available to support energy and carbon demands during a subsequent pathogen (Pseudomonas syringae) infection.

Altered amino acid levels after contact with a pathogen can have multiple and possibly conflicting functions. Several amino acids are precursors of important defense metabolites, e.g., alkaloids, phenylpropanoids, and glucosinolates. On the other hand, invasive pathogens like Pseudomonas syringae propagate in the apoplast and are exclusively dependent on extracellular plant metabolites. Reduction of sugars and amino acids in the apoplast and, as indicated by transcript changes, likely also other nitrogen resources should be an effective defense strategy that attenuates pathogen propagation and thereby increases the efficiency of other defense mechanisms (Seifi et al., 2013; Bezruczyk et al., 2018; Schwachtje et al., 2018). Several imprinted metabolic signals have been identified that may contribute to the modulation of SAR, including a glycerol-3-phosphate-dependent yet non-identified signal, azelaic acid, dehydroabietinal, jasmonic acid, and methyl salicylate (Dempsey and Klessig, 2012). The metabolic signals that are linked to SAR or other primed responses will yield intriguing novel insights into imprinted primary metabolism/ energy status and the function of such imprints for efficiently primed plant responses.

In their natural environment, plants usually face more than one type of stress. The physiological responses toward various stress combinations, simultaneous or successive, have been addressed by recent studies (reviewed in Suzuki et al., 2014). The effects on plant performance can be synergistic, neutral, or conflicting (Crisp et al., 2016; Lawas et al., 2018) and it will be a demanding task to unravel how metabolite-based priming and priming in general by a certain stress may influence plant responses to other types of stress.

\section{EXPERIMENTAL APPROACHES}

The successful search for priming-related metabolites relies on the timing of experiments. Mostly, stress studies focus on the immediate response of the plant system toward an applied stress, but rarely focus on the long-term effects on plant metabolism. The recovery phase after a stress event is crucial for the establishment of priming and should thus be studied more extensively. The history of plants prior to stress experiments is rarely controlled and comparable between experiments. These methodology details must be described in detail to enhance reproducibility of stress experiments.

Several factors interfere with the metabolic state of a plant during the recovery phase and must be experimentally addressed.
As described above, the metabolic composition of plant tissues is an integral of perceived environmental stresses (Gratani, 2014) and may lead to variation among individual plants even under standardized conditions (e.g., Sanchez et al., 2010). Metabolism is continuously regulated by the circadian clock (Farre and Weise, 2012) and this regulation also affects stress responses themselves on genetic and metabolic levels ( $\mathrm{Lu}$ et al., 2017). For example, glucosinolate accumulation follows the circadian rhythm in Arabidopsis and jasmonic acid-based defenses are synchronized with the likeliness of herbivore attack (Goodspeed et al., 2012). In return, several biotic stressors have recently been shown to influence the cycle length of the circadian clock, e.g., pathogens and insects (Sharma and Bhatt, 2015; Joo et al., 2018; Li et al., 2018). This requires experimental setups with extended sampling time points during the day. Also, the influence of the ontogenetic stage, i.e., the effects of endogenous physiological aging mechanisms, on induced metabolic responses should be addressed. Furthermore, as described above, priming-related metabolites may be stored in certain cell compartments (e.g., the vacuole). Subcellular localization of metabolites is difficult to assess but can be addressed by non-aqueous fractionation (Klie et al., 2011). Because temporal effects are essential for the assessment of induced, imprinted, and primed responses, care should be taken to design time-series experiments with extended and high temporal resolution including the coverage of diurnal changes. High replication is advised due to varying histories and developmental variation of individual plants (e.g., Peters et al., 2018), this applies particularly to field experiments. Further, the high chemodiversity of plant metabolites entails many different chemical properties. To find new candidates for priming, the application of multiple chromatography systems for untargeted metabolic profiling should be taken into account (e.g., Nakabayshi and Saito, 2015; Vasilev et al., 2016).

\section{CONCLUSION}

Recent publications tackle the study of metabolic imprints by analyses of recurrent perturbations or recovering plant systems and discover functions of novel primed metabolites and metabolic pathways (Gamir et al., 2014a; Balmer et al., 2015). Intensified research on the potential functions of metabolic imprints should be highly fruitful and yield novel insights into priming phenomena. This view is supported by recent findings that demonstrate surprisingly diverse effects of metabolites on stress metabolism, signaling, and transcription. The vast chemical diversity of plants will likely yield new candidates of metabolic regulation or priming.

Currently, the knowledge of the short- to long-term kinetics of metabolic imprints is fragmented. This fact renders vague the link between observed metabolic imprints and their potential function as priming signals or memory of past stress events. Except for the known signaling metabolites that are involved in primed plant responses, the nature, 
characteristics, and role of metabolic imprinting or priming remain mostly unknown not least because stress recovery is rarely investigated in depth by studies employing modern large-scale metabolomic, proteomic, transcriptomic, or epigenetic tools. From advanced analyses of metabolic imprints, we expect to discover new priming mechanisms and to gain insight into the major contributions of metabolism to priming and potentially short-lived or even longer-lasting non-neural, cellular memory.

\section{AUTHOR CONTRIBUTIONS}

JS and JK developed the concepts and wrote the manuscript with contributions of all other co-authors.

\section{REFERENCES}

Ahn, I. P., Kim, S., Lee, Y. H., and Suh, S. C. (2007). Vitamin B1-induced priming is dependent on hydrogen peroxide and the NPR1 gene in Arabidopsis. Plant Physiol. 143, 838-848. doi: 10.1104/pp.106.092627

Alcázar, R., Altabella, T., Marco, F., Bortolotti, C., Reymond, M., Koncz, C., et al. (2010). Polyamines: molecules with regulatory functions in plant abiotic stress tolerance. Planta 231, 1237-1249. doi: 10.1007/s00425-010-1130-0

An, Y., Zhang, M., Liu, G., Han, R., and Liang, Z. (2013). Proline accumulation in leaves of Periploca sepium via both biosynthesis up-regulation and transport during recovery from severe drought. PLoS One 8:e69942. doi: 10.1371/ journal.pone.0069942

Aranega-Bou, P., de la O Leyva, M., Finiti, I., Garcia-Agustin, P., and GonzálezBosch, C. (2014). Priming of plant resistance by natural compounds. Hexanoic acid as a model. Front. Plant Sci. 5:488. doi: 10.3389/fpls.2014.00488

Baena-González, E., and Sheen, J. (2008). Convergent energy and stress signaling. Trends Plant Sci. 13, 474-482. doi: 10.1016/j.tplants.2008.06.006

Baena-González, E. (2010). Energy signaling in the regulation of gene expression during stress. Mol. Plant 3, 300-313. doi: 10.1093/mp/ssp113

Bäurle, I. (2016). Plant heat adaptation: priming in response to heat stress. F1000Res. 5:694. doi: 10.12688/f1000research.7526.1

Balmer, A., Pastor, V., Gamir, J., Flors, V., and Mauch-Mani, B. (2015). The 'prime-ome': towards a holistic approach to priming. Trends Plant Sci. 20, 443-452. doi: 10.1016/j.tplants.2015.04.002

Balmer, A., Pastor, V., Glauser, G., and Mauch-Mani, B. (2018). Tricarboxylates induce defense priming against bacteria in Arabidopsis thaliana. Front. Plant Sci. 9:1221. doi: 10.3389/fpls.2018.01221

Bandoly, M., Grichnik, R., Hilker, M., and Steppuhn, A. (2016). Priming of anti-herbivore defence in Nicotiana attenuata by insect oviposition: herbivorespecific effects. Plant Cell Environ. 39, 848-859. doi: 10.1111/pce.12677

Benina, M., Obata, T., Mehterov, N., Ivanov, I., Petrov, V., Toneva, V., et al. (2013). Comparative metabolic profiling of Haberlea rhodopensis, Thellungiella halophyla, and Arabidopsis thaliana exposed to low temperature. Front. Plant Sci. 4, 1-11. doi: 10.3389/fpls.2013.00499

Bezruczyk, M., Yang, J., Eom, J.-S., Prior, M., Soss, D., Hartwig, T., et al. (2018). Sugar flux and signaling in plant-microbe interactions. Plant J. 93, 675-685. doi: 10.1111/tpj.13775

Bolton, M. D. (2009). Primary metabolism and plant defense-fuel for the fire. Mol. Plant-Microbe Interact. 22, 487-497. doi: 10.1094/MPMI-22-5-0487

Bonawitz, N. D., Soltau, W. L., Blatchley, M. R., Powers, B. L., Hurlock, A. K., Seals, L. A., et al. (2012). REF4 and RFR1, subunits of the transcriptional coregulatory complex mediator, are required for phenylpropanoid homeostasis in Arabidopsis. J. Biol. Chem. 287, 5434-5445. doi: 10.1074/jbc.M111.312298

Bruce, T. J. A., Matthes, M. C., Napier, J. A., and Pickett, J. A. (2007). Stressful "memories" of plants: evidence and possible mechanisms. Plant Sci. 173, 603-608. doi: 10.1016/j.plantsci.2007.09.002

\section{FUNDING}

We acknowledge the Max-Planck Society and the German Research Foundation (DFG) for funding the Collaborative Research Centre 973 "Priming and Memory of Organismic Responses to Stress" (www.sfb973.de). We thank the National Council for the Improvement of Higher Education-CAPES of Brazil-for the scholarship provided to AF.

\section{ACKNOWLEDGMENTS}

We acknowledge the long-standing support by Prof. Dr. L. Willmitzer, Prof. Dr. M. Stitt, and Prof. Dr. R. Bock (Max-PlanckInstitute of Molecular Plant Physiology, Potsdam, Germany).

Caldana, C., Degenkolbe, T., Cuadros-Inostroza, A., Klie, S., Sulpice, R., Leisse, A., et al. (2011). High-density kinetic analysis of the metabolomic and transcriptomic response of Arabidopsis to eight environmental conditions. Plant J. 67, 869-884. doi: 10.1111/j.1365-313X.2011.04640.x

Chevrot, R., Rosen, R., Haudecoer, E., Cirou, A., Shelp, B. J., Ron, E., et al. (2006). GABA controls the level of quorum-sensing signal in Agrobacterium tumefaciens. PNAS 103, 7460-7464. doi: 10.1073/pnas.0600313103

Cho, J. I., Ryoo, N., Eom, J. S., Lee, D. W., Kim, H. B., Jeong, S. W., et al. (2009). Role of the rice hexokinases OsHXK5 and OsHXK6 as glucose sensors. Plant Physiol. 149, 745-759. doi: 10.1104/pp.108.131227

Cho, Y. H., and Yoo, S. D. (2011). Signaling role of fructose mediated by FINS1/FBP in Arabidopsis thaliana. PLoS Genet. 7:e1001263. doi: 10.1371/ journal.pgen.1001263

Chubukov, V., Uhr, M., Le Chat, L., Kleijn, R. J., Jules, M., Link, H., et al. (2013). Transcriptional regulation is insufficient to explain substrate-induced flux changes in Bacillus subtilis. Mol. Syst. Biol. 9:709. doi: 10.1038/ msb. 2013.66

Conrath, U., Beckers, G. J. M., Langenbach, C. J. L., and Jaskiewicz, M. R. (2015). Priming for enhanced defense. Annu. Rev. Phytopathol. 53, 97-119. 10.1146/annurev-phyto-080614-120132

Crisp, P. A., Ganguly, D., Eichten, S. R., Borevitz, J. O., and Pogson, B. J. (2016). Reconsidering plant memory: Intersections between stress recovery, RNA turnover, and epigenetics. Sci. Adv. 2:e1501340. doi: 10.1126/sciadv.1501340

Cuevas, J. C., Lopez-Cobollo, R., Alcázar, R., Zarza, X., Koncz, C., Altabella, T., et al. (2008). Putrescine is involved in Arabidopsis freezing tolerance and cold acclimation by regulating abscisic acid levels in response to low temperature. Plant Physiol. 148, 1094-1105. doi: 10.1104/pp.108.122945

Dangl, J. L., and Jones, J. D. G. (2001). Plant pathogens and integrated defence ersponses to infection. Nature 411, 826-833. doi: 10.1038/35081161

De Deyn, B. G., Cornelisson, J. H. C., and Bardgett, R. D. (2008). Plant functional traits and soil carbon sequestration in contrasting biomes. Ecol. Lett. 11, 516-531. doi: 10.1111/j.1461-0248.2008.01164.x

Dempsey, D. M. A., and Klessig, D. F. (2012). SOS - too many signals for systemic acquired resistance? Trends Plant Sci. 17, 538-545. doi: 10.1016/j. tplants.2012.05.011

Ding, Y., Fromm, M., and Avramova, Z. (2012). Multiple exposures to drought 'train' transcriptional responses in Arabidopsis. Nat. Commun. 3:740. doi: $10.1038 /$ ncomms 1732

Dobrenel, T., Caldana, C., Hanson, J., Robaglia, C., Vincentz, M., Veit, B., et al. (2016). TOR signaling and nutrient sensing. Annu. Rev. Plant Biol. 67, 261-285. doi: 10.1146/annurev-arplant-043014-114648

Donohue, K. (2009). Completing the cycle: maternal effects as the missing link in plant life histories. Philos. Trans. R. Soc. B 364, 1059-1074. doi: 10.1098/rstb.2008.0291

Emmerlich, V., Linka, N., Reinhold, T., Hurth, M. A., Traub, M., Martinoia, E., et al. (2003). The plant homolog to the human sodium/dicarboxylic cotransporter 
is the vacuolar malate carrier. PNAS 100, 11122-11126. doi: 10.1073/ pnas. 1832002100

Engelberth, J., Alborn, H. T., Schmelz, E. A., and Tumlinson, J. H. (2004). Airborne signals prime plants against insect herbivore attack. Proc. Natl. Acad. Sci. U. S. A. 101, 1781-1785. doi: 10.1073/pnas.0308037100

Engelsdorf, T., Horst, R. J., Pröls, R., Pröschel, M., Dietz, F., Hückelhoven, R., et al. (2013). Reduced Carbohydrate Availability Enhances the Susceptibility of Arabidopsis toward Colletotrichum higginsianum. Plant Physiol. 162, 225-238. doi: 10.1104/pp.112.209676

Fait, A., Fromm, H., Walter, D., Galili, G., and Fernie, A. F. (2007). Highway or byway: the metabolic role of the GABA shunt in plants. Trends Plant Sci. 13, 14-19. doi: 10.1016/j.tplants.2007.10.005

Farre, E. V., and Weise, S. E. (2012). The interactions between the circadian clock and primary metabolism. Curr. Opin. Plant Biol. 15, 293-300. doi: 10.1016/j.pbi.2012.01.013

Figueroa, C. M., and Lunn, J. E. (2016). A tale of two sugars: trehalose 6-phosphate and sucrose. Plant Physiol. 172, 7-27. doi: 10.1104/pp.16.00417

Fraire-Velázquez, S., and Balderas-Hernández, V. E. (2013). "Abiotic stress in plants and metabolic responses" in Abiotic Stress - Plant Responses and Applications in Agriculture. eds. K. Vahdati and C. Leslie (Rijeka: InTech). doi: $10.5772 / 45842$

Francisco, M., Joseph, B., Caligagan, H., Li, B., Corwin, J. A., Lin, C., et al. (2016). The defense metabolite, allyl glucosinolate, modulates Arabidopsis thaliana biomass dependent upon the endogenous glucosinolate pathway. Front. Plant Sci. 7:774. doi: 10.3389/fpls.2016.00774

Frost, C. J., Mescher, M. C., Carlson, J. E., and De Moraes, C. M. (2008). Plant defense priming against herbivores: getting ready for a different battle. Plant Physiol. 146, 818-824. doi: 10.1104/pp.107.113027

Gamir, J., Sanchez-Bel, P., and Flors, V. (2014a). Molecular and physiological stages of priming: how plants prepare for environmental challenges. Plant Cell Rep. 33, 1935-1949. doi: 10.1007/s00299-014-1665-9

Gamir, J., Pastor, V., Kaever, A., Cerezo, M., and Flors, V. (2014b). Targeting novel chemical and constitutive primed metabolites against Plectosphaerella cucumerina. Plant J. 78, 227-240. doi: 10.1111/tpj.12465

Gaudinier, A., Tang, M., and Kliebenstein, D. J. (2015). Transcriptional networks governing plant metabolism. Curr. Plant Biol. 3-4, 56-64. doi: 10.1016/j. cpb.2015.07.002

Gomez-Ariza, J., Campo, S., Rufat, M., Estopa, M., Messeguer, J., San Segundo, B., et al. (2007). Sucrose-mediated priming of plant defense responses and broad-spectrum disease resistance by overexpression of the maize pathogenesisrelated PRms protein in rice plants. Mol. Plant-Microbe Interact. 20, 832-842. doi: 10.1094/MPMI-20-7-0832

González, A., and Hall, M. N. (2017). Nutrient sensing and TOR signaling in yeast and mammals. EMBO J. 36, 397-408. doi: 10.15252/embj.201696010

Goodspeed, D., Chehab, E. W., Min-Venditti, A., Braam, J., and Covington, M. F. (2012). Arabidopsis synchronizes jasmonate-mediated defense with insect circadian behavior. PNAS 109, 4674-4677. doi: 10.1073/ pnas. 1116368109

Gratani, L. (2014). Plant phenotypic plasticity in response to environmental factors. Adv. Bot. 2014:17. doi: 10.1155/2014/208747

Guy, C. L., Kaplan, F., Kopka, J., Selbig, J., and Hincha, D. K. (2008). Metabolomics of temperature stress. Physiol. Plant. 132, 220-235. doi: 10.1111/j.1399-3054.2007.00999.x

Guy, C. L. (2003). Freezing tolerance of plants: current understanding and selected emerging concepts. Can. J. Bot. 81, 1216-1223. doi: 10.1139/ b03-130

Hafke, J. B., Hafke, Y., Smith, J. A. C., Lüttge, U., and Thiel, G. (2003). Vacuolar malate uptake is mediated by an anion-selective inward rectifier. Plant $\mathrm{J}$. 35, 116-128. doi: 10.1046/j.1365-313X.2003.01781.x

Hawkes, C. V., and Sullivan, J. J. (2001). The impact of herbivory on plants in different resource conditions: a meta-analysis. Ecology 82, 2045-2058. doi: 10.1890/0012-9658(2001)082[2045:TIOHOP]2.0.CO;2

Hedrich, R., Sauer, N., and Neuhaus, H. E. (2015). Sugar transport across the plant vacuolar membrane: nature and regulation of carrier proteins. Curr. Opin. Plant Biol. 25, 63-70. doi: 10.1016/j.pbi.2015.04.008

Hemme, D., Veyel, D., Mühlhaus, T., Sommer, F., Jüppner, J., Unger, A. -K., et al. (2014). Systems-wide analysis of acclimation responses to long-term heat stress and recovery in the photosynthetic model organism Chlamydomonas reinhardtii. Plant Cell 26, 4270-4297. doi: 10.1105/tpc.114.130997

Henson, C. A., Duke, S. H., and Livingston, D. P. (2014). Metabolic changes in Avena sativa crowns recovering from freezing. PLoS One 9:e93085. doi: 10.1371/journal.pone.0093085

Hey, S. J., Byrne, E., and Halford, N. G. (2010). The interface between metabolic and stress signaling. Ann. Bot. 105, 197-203. doi: 10.1093/aob/mcp285

Hilker, M., Schwachtje, J., Baier, M., Balazadeh, S., Bäurle, I., Geiselhardt, S., et al. (2015). Priming and memory of stress responses in organisms lacking a nervous system. Biol. Rev. 91, 1118-1133. doi: 10.1111/brv.12215

Hincha, D. K., and Zuther, E. (2014). "Introduction: plant cold acclimation and freezing tolerance" in Methods in molecular biology. eds. D. K. Hincha and E. Zuther, Vol. 1166 (New York: Springer), 1-6.

Hincha, D. K., Popova, A. V., and Cacela, C. (2006). "Effects of sugars on the stability and structure of lipid membranes during drying" in Advances in planar lipid bilayers and liposomes. ed. A. Leitmannova Liu, Vol. 3 (Amsterdam, The Netherlands: Elsevier), 189-217. doi: 10.1016/S1554-4516(05)03006-1

Ibragimova, S. S., Kolodyazhnaya, Y. S., Gerasimova, S. V., and Kochetov, A. V. (2012). Partial suppression of gene encoding proline dehydrogenase enhances plant tolerance to various abiotic stresses. Russ. J. Plant Physiol. 59, 88-96. doi: 10.1134/S1021443712010086

Jakab, G., Cottier, V., Toquin, V., Rigoli, G., Zimmerli, L., Métraux, J. P., et al. (2001). $\beta$-Aminobutyric acid-induced resistance in plants. Eur. J. Plant Pathol. 107, 29-37. doi: 10.1023/A:1008730721037

Jaskiewicz, M., Conrath, U., and Peterhaensel, C. (2011). Chromatin modification acts as a memory for systemic acquired resistance in the plant stress response. EMBO Rep. 12, 50-55. doi: 10.1038/embor.2010.186

Jia, Z. H., Zou, B. H., Wang, X. M., Qiu, J. A., Ma, H., Gou, Z. H., et al. (2010). Quercetin-induced $\mathrm{H}_{2} \mathrm{O}_{2}$ mediates the pathogen resistance against Pseudomonas syringae pv. Tomato DC3000 in Arabidopsis thaliana. Biochem. Biophis. Res. Commun. 396, 522-527. doi: 10.1016/j.bbrc.2010.04.131

Jisha, K. C., Vijayakumari, K., and Puthur, J. T. (2013). Seed priming for abiotic stress tolerance: an overview. Acta Physiol. Plant. 35, 1381-1396. doi: $10.1007 / \mathrm{s} 11738-012-1186-5$

Joo, Y., Schuman, M. C., Goldberg, J. K., Wissgott, A., Kim, S. G., and Baldwin, I. T. (2018). Herbivory elicits changes in green leaf volatile production via jasmonate signaling and the circadian clock. Plant Cell Environ. 41, 2577-2588. doi: 10.1111 pce. 13474

Kaplan, F., Kopka, J., Haskell, D. W., Zhao, W., Schiller, K. C., Gatzke, N., et al. (2004). Exploring the temperature-stress metabolome of Arabidopsis. Plant Physiol. 136, 4159-4168. doi: 10.1104/pp.104.052142

Kaplan, F, Kopka, J., Sung, D. Y., Zhao, W., Popp, M., Porat, R., et al. (2007). Transcript and metabolite profiling during cold acclimation of Arabidopsis reveals an intricate relationship of cold-regulated gene expression with modifications in metabolite content. Plant J. 50, 967-981. doi: 10.1111/j.1365-313X.2007.03100.x

Katz, E., Nisani, S., Yadav, B. S., Woldemariam, M. G., Shai, B., Obolski, U., et al. (2015). The glucosinolate breakdown product indole-3-carbinol acts as an auxin antagonist in roots of Arabidopsis thaliana. Plant J. 82, 547-555. doi: $10.1111 /$ tpj.12824

Kim, S. G., Jon, F., Gaquerel, E., Gulati, J., and Baldwin, I. T. (2011). Tissue specific diurnal rhythms of metabolites and their regulation during herbivore attack in a native tobacco, Nicotiana attenuata. PLoS One 6:e26214. doi: 10.1371/journal.pone.0026214

Klie, S., Krueger, S., Krall, L., Giavalisco, P., Flügge, U. I., Willmitzer, L., et al. (2011). Analysis of the compartmentalized metabolome-a validation of the non-aqueous fractionation technique. Front. Plant Sci. 2:55. doi: 10.3389/ fpls.2011.00055

Krasensky, J., and Jonak, C. (2012). Drought, salt, and temperature stressinduced metabolic rearrangements and regulatory networks. J. Exp. Bot. 63, 1593-1608. doi: 10.1093/jxb/err460

Lawas, L. M. F., Zuther, E., Jagadish, S. V. K., and Hincha, D. K. (2018). Molecular mechanisms of combined heat and drought stress resilience in cereals. Curr. Opin. Plant Biol. 45, 212-217. doi: 10.1016/j.pbi.2018.04.002

Lecompte, F., Nicot, P. C., Ripoll, J., Abro, M. A., Raimbault, A. K., Lopez-Lauri, F., et al. (2017). Reduced susceptibility of tomato stem to the necrotrophic fungus Botrytis cinerea is associated with a specific adjustment of fructose content in the host sugar pool. Ann. Bot. 119, 931-943. doi: 10.1093/aob/mcw240 
Lee, Y. P., Funk, C., Erban, A., Kopka, J., Köhl, K. I., Zuther, E., et al. (2016). Salt stress responses in a geographically diverse collection of Eutrema/Thellungiella spp. Accessions. Funct. Plant Biol. 43, 590-606. doi: 10.1071/FP15285

Legocka, J., Sobieszczuk-Nowicka, E., Ludwicki, D., and Lehmann, T. (2017). Putrescine catabolism via DAO contributes to proline and GABA accumulation in roots of lupine seedlings growing under salt stress. Acta Soc. Bot. Pol. 86:3549. doi: 10.5586/asbp.3549

Lehmann, M., Laxa, M., Sweetlove, L. J., Fernie, A. R., and Obata, T. (2012). Metabolic recovery of Arabidopsis thaliana roots following cessation of oxidative stress. Metabolomics 8, 143-153. doi: 10.1007/s11306-011-0296-1

Lemoine, R., La Camera, S., Atanassova, R., Dédaldéchamp, F., Allario, T., Pourtau, N., et al. (2013). Source-to-sonk transport of sugar and regulation by environmental factors. Front. Plant Sci. 4:272. doi: 10.3389/ fpls.2013.00272

Li, P., Wind, J. J., Shi, X., Zhang, H., Hanson, J., Smeekens, S. C., et al. (2011). Fructose sensitivity is suppressed in Arabidopsis by the transcription factor ANAC089 lacking the membrane-bound domain. Proc. Natl. Acad. Sci. U. S. A. 108, 3436-3441. doi: 10.1073/pnas.1018665108

Li, L., and Sheen, J. (2016). Dynamic and diverse sugar signalling. Curr. Opin. Plant Biol. 33, 116-125. doi: 10.1016/j.pbi.2016.06.018

Li, Z., Bonaldi, K., Uribe, F., and Pruneda-Paz, J. L. (2018). A localized Pseudomonas syringae infection triggers systemic clock responses in Arabidopsis. Curr. Biol. 28, 630-639. doi: 10.1016/j.cub.2018.01.001

Liang, X., Zhang, L., Natarajan, S. K., and Becker, D. F. (2013). Proline mechanisms of stress survival. Antioxid. Redox Signal. 19, 998-1011. doi: 10.1089/ ars.2012.5074

Liu, G., Ji, Y., Bhuiyan, N. H., Pilot, G., Selvaraj, G., Zou, J., et al. (2010). Amino acid homeostasis modulates salicylic acid-associated redox status and defense responses in Arabidopsis. Plant Cell 22, 3845-3863. doi: 10.1105/tpc.110.079392

Liu, J. -H., Wang, W., Wu, H., Gong, X., and Moriguchi, T. (2015). Polyamines function in stress tolerance: from synthesis to regulation. Frontiers in Plant Science 6:827. doi: 10.3389/fpls.2015.00827

Livingston, D. P. 3rd., Hincha, D. K., and Heyer, A. G. (2009). Fructan and its relationship to abiotic stress tolerance in plants. Cell. Mol. Life Sci. 66, 2007-2023. doi: 10.1007/s00018-009-0002-x

Lu, H., McClung, R., and Zhang, C. (2017). Tick tock: circadian regulation of plant innate immunity. Annu. Rev. Phytopathol. 55, 287-311. doi: 10.1146/ annurev-phyto-080516-035451

Mackie, A., Keseler, I. M., Nolan, L., Karp, P. D., and Paulsen, I. T. (2013). Dead end metabolites-defining the known unknowns of the E. coli metabolic network. PLoS One 8:e75210. doi: 10.1371/journal.pone.0075210

Malinovski, F. G., Thomson, M.-L. F., Nintemann, S. J., Jagd, L. M., Bourgine, B., Burow, M., et al. (2017). An evolutionarily young defense metabolite influences the root growth of plants via the ancient TOR signaling pathway. elife 6:e29353. doi: 10.7554/eLife.29353

Mauch-Mani, B., Baccelli, I., Luna, E., and Flors, V. (2017). Defense priming: an adaptive part of induced resistance. Annu. Rev. Plant Biol. 68, 485-512. doi: 10.1146/annurev-arplant-042916-041132

Martinoia, E., Maeshima, M., and Neuhaus, H. E. (2007). Vacuolar transporters and their essential role in plant metabolism. J. Exp. Bot. 58, 83-102. doi: 10.1093/jxb/erl183

Martinoia, E., Meyer, S., De Angeli, A., and Nagy, R. (2012). Vacuolar transporters in their physiological context. Annu. Rev. Plant Biol. 63, 183-213. doi: 10.1146/annurev-arplant-042811-105608

Mazucotelli, E., Tartari, A., Cattivelli, L., and Forlani, G. (2006). Metabolism of $\gamma$-aminobutyric acid during cold acclimation and freezing and its relationship to frost tolerance in barley and wheat. J. Exp. Bot. 57, 3755-3766. doi: $10.1093 / \mathrm{jxb} / \mathrm{erl} 141$

Michaeli, S., and Fromm, H. (2015). Closing the loop on the GABA shunt in plants: are GABA metabolism and signalling entwined? Front. Plant Sci. 4:419. doi: $10.3389 /$ fpls.2015.00419

Miller-Fleming, L., Olin-Sandoval, V., Campbell, K., and Ralser, M. (2015). Remaining Mysteries of Molecular Biology: The Role of Polyamines in the Cell. J. Mol. Biol. 427, 3389-3406. doi: 10.1016/j.jmb.2015.06.020

Moore, B., Zhou, L., Rolland, F., Hall, Q., Cheng, W. H., Liu, Y. X., et al. (2003). Role of the Arabidopsis glucose sensor HXK1 in nutrient, light, and hormonal signaling. Science 300, 332-336. doi:10.1126/science.1080585
Moyankova, D., Mladenov, P., Berkov, S., Pesehv, D., Georgieva, D., and Djilianov, D. (2014). Metabolic profiling of the resurrection plant Haberlea rhodopensis during desiccation and recovery. Physiol. Plant. 152, 675-687. doi: 10.1111/ ppl.12212

Nakabayshi, R., and Saito, K. (2015). Integrated metabolomics for abiotic stress responses in plants. Curr. Opin. Plant Biol. 24, 10-16. doi: 10.1016/j. pbi.2015.01.003

Návarová, H., Bernsdorff, F., Döring, A. C., and Zeier, J. (2012). Pipecolic acid, an endogenous mediator of defense amplification and priming, is a critical regulator of inducible plant immunity. Plant Cell 24, 5123-5141. doi: $10.1105 /$ tpc.112.103564

Naya, L., Ladrera, R., Ramos, J., González, E. M., Arrese-Igor, C., Minchin, F. R., et al. (2007). The response of carbon metabolism and antioxidant defenses of alfalfa nodules to drought stress and to the subsequent recovery of plants. Plant Physiol. 144, 1104-1114. doi: 10.1104/pp.107.099648

Neuhaus, H. E. (2007). Transport of primary metabolites across the plant vacuolar membrane. FEBS Lett. 581, 2223-2226. doi: 10.1016/j.febslet.2007.02.003

Onwuka, B., and Mang, B. (2018). Effects of soil temperature on some soil properties and plant growth. Adv. Plants Agric. Res. 8, 34-37. doi: 10.15406/ apar.2018.08.00288

Pagter, M., Alpers, J., Erban, A., Kopka, J., Zuther, E., and Hincha, D. K. (2017). Rapid transcriptional and metabolic regulation of the deacclimation process in cold acclimated Arabidopsis thaliana. BMC Genomics 18:731. doi: 10.1186/s12864-017-4126-3

Pasini, A., Caldarera, C. M., and Giordano, E. (2014). Chromatin remodeling by polyamines and polyamine analogs. Amino Acids 46, 595-603. doi: 10.1007/ s00726-013-1550-9

Pastor, V., Balmer, A., Gamir, J., Flors, F., and Mauch-Mani, B. (2014). Preparing to fight back: generation and storage of priming compounds. Front. Plant Sci. 5:295. doi: 10.3389/fpls.2014.00295

Peters, K., Worrich, A., Weinhold, A., Alka, O., Balcke, G., Birkemeyer, C., et al. (2018). Current challenges in plant eco-metabolomics. Int. J. Mol. Sci. 19, 1385-1422. doi: 10.3390/ijms19051385

Pinson, B., Vaur, S., Sagot, I., Coulpier, F., Lemoine, S., and Daignan-Fornier, B. (2009). Metabolic intermediates selectively stimulate transcription factor interaction and modulate phosphate and purine pathways. Genes Dev. 23, 1399-1407. doi: 10.1101/gad.521809

Plaxton, W. C. (2005). "Principles of metabolic control" in Functional metabolism: regulation and adaptation 1. ed. K. B. Storey, Vol. 1 (New Jersey: Wiley). doi: 10.1002/047167558X.ch1

Pommerrenig, B., Ludewig, F., Cvetkovic, J., Trentmann, O., Klemens, P. A. W., and Neuhaus, H. E. (2018). In concert: orchestrated changes in carbohydrate homeostasis are critical for plant abiotoc stress tolerance. Plant Cell Physiol. 59, 1290-1299. doi: 10.1093/pcp/pcy037

Pozo, M. J., Verhage, A., García-Andrade, J., García, J. M., and Azcón-Aguilar, C. (2009). "Priming plant defences against pathogens by arbuscular mycorrhizal fungi" in Mycorrhizas: functional processes and ecological impact. eds. C. AzcónAguilar, J. M. Barea, S. Gianinazzi, and V. Gianinazzi-Pearson (Berlin and Heidelberg: Springer), 137-149. doi: 10.1007/978-3-540-87978-7_9

Qamar, A., Mysore, K. S., and Senthil-Kumar, M. (2015). Role of proline and pyrroline-5-carboxylate metabolism in plant defense against invading pathogens. Front. Plant Sci. 6:503. doi: 10.3389/fpls.2015.00503

Rasmann, S., De Vos, M., Casteel, C. L., Tian, D., Halitschke, R., Sun, J. Y., et al. (2011). Herbivory in the previous generation primes plants for enhanced insect resistance. Plant Physiol. 158, 854-863. doi: 10.1104/pp.111.187831

Rexin, D., Meyer, C., Robaglia, C., and Veit, B. (2015). TOR signalling in plants. Biochem. J. 470, 1-14. doi: 10.1042/BJ20150505

Rojas, C. M., Senthil-Kumar, M., Tzin, V., and Mysore, K. S. (2014). Regulation of primary plant metabolism during plant-pathogen interactions and its contributions to plant defense. Front. Plant Sci. 5:17. doi: 10.3389/ fpls.2014.00017

Sagor, G. H. M., Berberich, T., Takahashi, Y., Niitsu, M., and Kusano, T. (2013). The polyamine spermine protects Arabidopsis from heat stress-induced damage by increasing expression of heat shock-related genes. Transgenic Res. 22, 595-605. doi: 10.1007/s11248-012-9666-3

Sampaio, L., Edrada-Ebel, R., and Da Costa, F. B. (2015). Effect of the environment on the secondary metabolic profile of Tithonia diversifolia: a model for 
environmental metabolomics of plants. Sci. Rep. 6:29265. doi: 10.1038/ srep29265

Sanchez, D. H., Szymanski, J., Erban, A., Udvardi, M. K., and Kopka, J. (2010). Mining for robust transcriptional and metabolic responses to long-term salt stress: a case study on the model legume Lotus japonicus. Plant Cell Environ. 33, 468-480. doi: 10.1111/j.1365-3040.2009.02047.x

Sani, E., Herzyk, P., Perrella, G., Colot, V., and Amtmann, A. (2013). Hyperosmotic priming of Arabidopsis seedlings establishes a long-term somatic memory accompanied by specific changes of the epigenome. Genome Biol. 14:R59. doi: $10.1186 / g b-2013-14-6-r 59$

Scholz, S. S., Reichelt, M., Mekonnen, D. W., Ludewig, F., and Mithöfer, A. (2015). Insect herbivory-elicited gaba accumulation in plants is a wound-induced, direct, systemic, and jasmonate-independent defense response. Front. Plant Sci. 6:1128. doi: 10.3389/fpls.2015.01128

Schuman, M. C., and Baldwin, I. T. (2015). The layers of plant responses to herbivores. Annu. Rev. Entomol. 61, 373-394. doi: 10.1146/annurevento-010715-023851

Schwachtje, J., and Baldwin, I. T. (2006). Why does herbivore attack reconfigure primary metabolism? Plant Physiol. 146, 845-851. doi: 10.1104/ pp.107.112490

Schwachtje, J., Fischer, A., Erban, A., and Kopka, J. (2018). Primed primary metabolism in systemic leaves: a functional systems analysis. Sci. Rep. 8:216. doi: 10.1038/s41598-017-18397-5

Schwender, J., König, C., Klapperstück, M., Heinzel, N., Munz, E., Hebbelmann, I., et al. (2014). Transcript abundance on its own cannot be used to infer fluxes in central metabolism. Front. Plant Sci. 5:668. doi: 10.3389/ fpls.2014.00668

Seip, B., and Innis, C. A. (2016). How widespread is metabolite sensing by ribosome-arresting nascent peptides? J. Mol. Biol. 428, 2217-2227. doi: 10.1016/j.jmb.2016.04.019

Seifi, H. S., Van Bockhaven, J., Angenon, G., and Höfte, M. (2013). Glutamate metabolism in plant disease and defense: friend or foe? Mol. Plant-Microbe Interact. 26, 475-485. doi: 10.1094/MPMI-07-12-0176-CR

Sharma, S., and Verslues, P. E. (2010). Mechanisms independent of abscisic acid (ABA) or proline feedback have a predominant role in transcriptional regulation of proline metabolism during low water potential and stress recovery. Plant Cell Environ. 33, 1838-1851. doi: 10.1111/j.1365-3040.2010.02188.x

Sharma, M., and Bhatt, D. (2015). The circadian clock and defence signalling in plants. Mol. Plant Pathol. 16, 210-218. doi: 10.1111/mpp.12178

Shellhammer, J. P., Morin-Kensicki, E., Matson, J. P., Yin, G., Isom, D. G., Campbell, S., et al. (2017). Amino acid metabolites that regulate G protein signaling during osmotic stress. PLoS Genet. 13:e1006829. doi: 10.1371/ journal.pgen.1006829

Shelp, B. J., Bozzo, G. G., Trobacher, C. P., Zarei, A., Deyman, K. L., and Brikis, C. J. (2012). Hypothesis/review: Contribution of putrescine to 4-aminobutyrate (GABA) production in response to abiotic stress. Plant Sci. 193-194, 130-135. doi: 10.1016/j.plantsci.2012.06.001

Shen, Y., Issakidis-Bourguet, E., and Zhou, D.-X. (2016). Perspectives on the interactions between metabolism, redox, and epigenetics in plants. J. Exp. Bot. 67, 5291-5300. doi: 10.1093/jxb/erw310

Signorelli, S., Dans, P. D., Coitino, E. L., Borsani, O., and Monza, J. (2015). Connecting proline and a-aminobutyric acid in stressed plants through non-enzymatic reactions. PLoS One 10:e0115349. doi: 10.1371/journal. pone.0115349

Stief, A., Altmann, S., Hoffmann, K., Pant, B. D., Scheible, W. R., and Bäurle, I. (2014). Arabidopsis miR156 regulates tolerance to recurring environmental stress through SPL transcription factors. Plant Cell 26, 1792-1807. doi: 10.1105/ tpc.114.123851

Stuttmann, J., Hubberten, H.-M., Rietz, S., Kaur, J., Muskett, P., and Guerois, R., et al. (2011). Perturbation of Arabidopsis amino acid metabolism causes incompatibility with the adapted biotrophic pathogen Hyaloperonospora arabidopsidis. Plant Cell 23, 2788-2803. doi: 10.1105/ tpc. 111.087684

Sultan, S. E. (2000). Phenotypic plasticity for plant development, function and life history. Trends Plant Sci. 5, 537-542. doi: 10.1016/S1360-1385(00)01797-0

Suzuki, N., Rivero, R. M., Shulaev, V., Blumwald, E., and Mittler, R. (2014). Abiotic and biotic stress combinations. New Phytol. 203, 32-43. doi: 10.1111/ nph. 12797
Suzuki, N., Koussevitzky, S., Mittler, R., and Miller, G. (2011). ROS and redox signalling in the responses of plants to abiotic stress. Plant Cell Environ. 35, 259-270. doi: 10.1111/j.1365-3040.2011.02336.x

Szabados, L., and Savouré, A. (2009). Proline: a multifunctional amino acid. Trends Plant Sci. 15, 89-97. doi: 10.1016/j.tplants.2009.11.009

Szekowka, M., Heise, R., Tohge, T., Nunes-Nesi, A., Vosloh, D., and Huege, J., et al. (2013). Metabolic fluxes in an illuminated Arabidopsis Rosette. Plant Cell 25, 694-714. doi: 10.1105/tpc.112.106989

Taji, T., Seki, M., Satou, M., Sakurai, T., Kobayashi, M., and Ishiyama, K., et al. (2004). Comparative genomics in salt tolerance between Arabidopsis and arabidopsis-related halophyte salt cress using arabidopsis microarray. Plant Physiol. 135, 1697-1709. doi: 10.1104/pp.104.039909

Tarkowski, L. P., and Van den Ende, W. (2015). Cold tolerance triggered by soluble sugars: a multifaceted countermeasure. Front. Plant Sci. 6:203. doi: 10.3389/fpls.2015.00203

Tauzin, A. S., and Giardina, T. (2014). Sucrose and invertases, a part of the plant defense response to the biotic stresses. Front. Plant Sci. 5:293. doi: $10.3389 /$ fpls.2014.00293

Thellier, M., and Lüttge, U. (2013). Plant memory: a tentative model. Plant Biol. 15, 1-12. doi: 10.1111/j.1438-8677.2012.00674.x

Thibaud, M. C., Gineste, S., Nussaume, L., and Robaglia, C. (2004). Sucrose increases pathogenesis-related PR-2 gene expression in Arabidopsis thaliana through an SA-dependent but NPR1-independent signaling pathway. Plant Physiol. Biochem. 42, 81-8. doi: 10.1016/j.plaphy.2003.10.012

Thomashow, M. F. (1999). Plant cold acclimation: freezing tolerance genes and regulatory mechanisms. Annu. Rev. Plant Physiol. Plant Mol. Biol. 50, 571-599. doi: 10.1146/annurev.arplant.50.1.571

Tiburcio, A. F., Altabella, T., Bitrián, M., and Alcazár, R. (2014). The roles of polyamines during the lifespan of plants: from development to stress. Planta 240, 1-18. doi: 10.1007/s00425-014-2055-9

Tognetti, J. A., Pontis, H. G., and Martínez-Noël, G. M. A. (2013). Sucrose signalling in plants-a world yet to be explored. Plant Signal. Behav. 8:e23316. doi: $10.4161 /$ psb.23316

Tohge, T., Schnell Ramos, M., Nunes-Nesi, A., Mutwil, M., Giavalisco, P., Steinhauser, D., et al. (2011). Toward the storage metabolome: profiling the Barley Vacuole. Plant Physiol. 157, 1469-1482. doi: 10.1104/pp.111.185710

Urbanczyk-Wochniak, E., Baxter, C., Kolbe, A., Kopka, J., Sweetlove, L. J., and Fernie, A. R. (2005). Profiling of diurnal patterns of metabolite and transcript abundance in potato (Solanum tuberosum) leaves. Planta 221, 891-903. doi: 10.1007/s00425-005-1483-y

Van Loon, L. C. (2007). Plant responses to plant growth-promoting rhizobacteria. Eur. J. Plant Pathol. 119, 243-254. doi: 10.1007/s10658-007-9165-1

Vancova, R., Dobra, J., and Storchová, H. (2012). Recovery from drought stress in tobacco. Plant Signal. Behav. 7, 19-21. doi: 10.4161/psb.7.1.18375

Van der Ent, S., Van Wees, S. C. M., and Pieterse, C. M. J. (2009). Jasmonate signaling in plant interactions with resistance-inducing beneficial microbes. Phytochemistry 70, 1581-1588. doi: 10.1016/j.phytochem.2009.06.009

Van der Knaap, J. A., and Verrijzer, C. P. (2016). Undercover: gene control by metabolites and metabolic enzymes. Genes Dev. 30, 2345-2369. doi: $10.1101 /$ gad.289140.116

Vasilev, N., Boccard, J., Lang, G., Grömping, U., Fischer, R., Goepfert, S., et al. (2016). Structured plant metabolomics for the simultaneous exploration of multiple factors. Sci. Rep. 6:37390. doi: 10.1038/srep37390

Wedeking, R., Maucourt, M., Deborde, C., Moing, A., Gibon, Y., Goldbach, H. E., et al. (2018). ${ }^{1} \mathrm{H}-\mathrm{NMR}$ metabolomic profiling reveals a distinct metabolic recovery response in shoots and roots of temporarily drought-stressed sugar beets. PLoS One 13:e0196102. doi: 10.1371/journal.pone.0196102

Weeda, S., Zhang, N., Zhao, X., Ndip, G., Guo, Y., Buck, G. A., et al. (2014). Arabidopsis transcriptome analysis reveals key roles of melatonin in plant defense systems. PLoS One 9:e93462. doi: 10.1371/journal. pone.0093462

Xiao, W., Sheen, J., and Jang, J. C. (2000). The role of hexokinase in plant sugar signal transduction and growth and development. Plant Mol. Biol. 44, 451-461. doi: 10.1023/A:1026501430422

Xiao, Y., Savchenk, T., Baidoo, E. E. K., Chehab, W. E., Hayden, D. M., Tolstikov, V., et al. (2012). Retrograde signaling by the plastidial metabolite MEcPP regulates expression of nuclear stress-response genes. Cell 149, 1525-1535. doi: $10.1016 /$ j.cell.2012.04.038 
Zeier, J. (2013). New insights into the regulation of plant immunity by amino acid metabolic pathways. Plant Cell Environ. 36, 2085-2103. doi: 10.1111/ pce. 12122

Zhang, S. J., Yang, X., Sun, M. W., Sun, F., Deng, S., and Dong, H. S. (2009). Riboflavin-induced priming for pathogen defense in Arabidopsis thaliana. J. Integr. Plant Biol. 51, 167-174. doi: 10.1111/j.1744-7909.2008.00763.x

Zhou, S., Lou, Y.-R., Tzin, V., and Jander, G. (2015). Alteration of plant primary metabolism in response to insect herbivory. Plant Physiol. 169, 1488-1498. doi: $10.1104 /$ pp.15.01405

Zimmerli, L., Métraux, J. P., and Mauch-Mani, B. (2001). Beta-aminobutyric acid-induced protection of Arabidopsis against the necrotrophic fungus Botrytis cinerea. Plant Physiol. 126, 517-523. doi: 10.1104/pp.126.2.517

Zuther, E., Juszczak, I., Lee, Y. P., Baier, M., and Hincha, D. (2015). Timedependent deacclimation after cold acclimation in Arabidopsis thaliana accessions. Sci. Rep. 5:12199. doi: 10.1038/srep12199
Zuther, E., Schaarschmidt, S., Fischer, A., Erban, A., Pagter, M., Mubeen, U., et al. (2018). Molecular determinants of increased freezing tolerance due to low temperature memory in Arabidopsis. Plant Cell Environ. doi: 10.1111/pce.13502

Conflict of Interest Statement: The authors declare that the research was conducted in the absence of any commercial or financial relationships that could be construed as a potential conflict of interest.

Copyright (c) 2019 Schwachtje, Whitcomb, Firmino, Zuther, Hincha and Kopka. This is an open-access article distributed under the terms of the Creative Commons Attribution License (CC BY). The use, distribution or reproduction in other forums is permitted, provided the original author(s) and the copyright owner(s) are credited and that the original publication in this journal is cited, in accordance with accepted academic practice. No use, distribution or reproduction is permitted which does not comply with these terms. 